training and attainments. He illustrates his point by giving an outline of the organisation of a typical chemical works in Germany. The management consists of a business man, a chemist and an engineer, and attached to each department is a special research laboratory. Both the laboratories and workshops are splendidly fitted with every appliance necessary for carrying out the most complicated and exact operations. The expenditure upon chemicals, books and apparatus would appear to a British manufacturing company to be absolute lunacy, the Badische Anilin und Soda Fabrik alone spending more than 5oool. a year on glass and porcelain apparatus. The consulting library attached to the laboratories of $\mathbf{F}$. Baeyer and Co., of Elberfeld, contains no less than fourteen thousand volumes and twenty-three thousand pamphlets of an original character.

As to the methods of research, when a new compound has been discovered which is found to have, say, dyeing properties, it is sent to the dyeing department, where a chemist, who has made a speciality of that particular branch of chemistry, subjects it to the most exhaustive tests, and tries its behaviour on cotton, wool, silk, paper, leather, \&c. Should any of these tests turn out in a satisfactory manner, the substance is then subjected to tests on a semi-manufacturing scale. Again, a new preparation which may be expected to possess therapeutic properties is sent to the medical department, where its physiological effects are tried. These articles having successfully passed through the experimental stages, the business man is called in, and they are placed on the market. Circulars and pamphlets are sent out, which set forth the effects and uses of the articles. These circulars are printed in all the European languages, and often in those of Asia. Samples are sent out, and travellers, who are accomplished chemists, visit works and business houses where the articles may be used. These men place their knowledge and skill at the service of the consumer, while they demonstrate how the articles may be used to the greatest advantage: In no case do they endeavour to plant their products upon their customers against their will, and, if necessary, the articles are so far as possible modified to meet their customers' tastes and prejudices. Little or nothing is left to chance; everything that ingenuity and business experience can suggest is resorted to in order to obtain the market. ${ }^{1}$

Prof. Haller recognises that the patent laws of 1878 have been of great benefit to the German manufacturers. But patent laws are only useful when there are inventions to be patented and processes to be protected. He further recognises that the mineral wealth of Germany has been of incalculable value to the nation, because it has, to a large extent, rendered it independent of outside nations for its raw products. For example, the wonderful deposits of Stassfurt enable the Germans not only to supply themselves, but the world at large, with potassium salts.

Prof. Haller considers the scientific training obtainable at the universities and polytechnics to be the main reason of the astonishing development of the German chemical industry. It must not be forgotten that beside the universities and polytechnics, there are special academies where the general outlines of chemistry are taught, and where special applications of science to

1 "The British merchant sells the goods which he deals in and has selected himself. and leaves it to the customer to adapt himself to th merchandise. The German individualises and meets the wants of hi customers; he adapts his merchandise, credit, conditions of sales, decoration, packing, \&c., to the wants and devires of his client Thus be often gains a start, for the buyer is but seldom in a position to value quality and prices. Another point is forced on the observer, and this is the great start in scientific training which Germany can boast of." (Diplomatic and Consular Reports, No. 2484.) industry are studied. For example, the Mulhausen School of Dyeing and Printing, the Electrochemical Institute at Darmstadt, the Mining Academy at Freiberg. Then there are purely technical schools, where such subjects as sugar making, brewing, pottery, \&c., are taught.

The Germans believe in an aristocracy of brains, and owing to this and the high social standing which follows educational success, many are attracted to the universities, not simply to obtain university polish, but to devote their energies to hard study and scientific research. The British man of science is inclined to look upon the commercial applications of science as beneath him. But is there not a tendency for the German man of science to go to the other extreme, and look upon science as simply an aid to commercial success? We do not want to commercialise science, but we do desire to make commercial methods more scientific.

We await with interest Prof. Haller's further article upon the chemical industry of England, Russia and the United States.

F. Mollwo Perkin.

\section{REMARKABLE WINTERS.}

$T$ HE period of winter for purposes of the present article may be defined as embracing the six months October to March, although when dividing the year into four seasons, the winter then for meteorological purposes is comprised in the months of December, January and February. Generally speaking, temperature is the most important factor in deciding whether a winter is severe or otherwise, although there are other aspects which render the weather disagreeable. When gales occur with more than ordinary frequence the winter is characterised as stormy, and similarly when rains are heavy and of common occurrence the winter is characterised as wet. Our winters in England vary to so great an extent in their general character that it is not always easy to say with scientific precision whether a winter may or may not be styled as remarkable. It generally happens that when a winter is cold the weather is fairly dry and there are fewer gales than usual, although, on the other hand, the quiet conditions are favourable to fog formation. In a mild winter the weather is usually wet, and storms are of common occurrence, the mild weather being very intimately associated with the arrival of cyclonic disturbances from the Atlantic, and as the common track of these storms takes the centres of the disturbances over the northern portion of our area we, in England, for the most part experience the south-westerly and westerly winds which bring us the moist and warm air from off the ocean to the westward of us. For the purposes of comparison the data used refer almost wholly to Greenwich, where the long series of observations made at our national observatory is eminently suitable, and, so far as the weather of a winter is concerned, there is probably no real disadvantage in restricting the area of comparison to one locality, since in a general sense it would be equally applicable to most other parts of England. The coldest winters of recent years are those of $1890-1$ and $1894-5$, in which there were respectively ten and eleven days with the temperature below $20^{\circ} \mathrm{F}$. at Greenwich. In the last sixty years there have only been two other winters with so low a temperature on ten days; these were $1854-5$ with twelve such cold days, and I $880-1$ with ten days. The greatest number of davs with frost during the period of sixty years was eighty in the winter six months of $1887-8$, and the winters with seventy or more days of frost were $1844-5, \quad 1846-7, \quad 1854-5, \quad 1874-5, \quad 1878-9, \quad 1879-80$, I $885-6$, I $886-7$, I $887-8$ and I $890-I$. Using this as a test for the mildness of the winter, the least number 
of frosty days was nineteen in the winter of $1883-4$, and there were fewer than thirty-five days with frost in the winters of $1845-6,1850-1,1858-9,1862-3,1865-6,1876-7$, $1881-2,1883-4,1895-6$ and $1897-8$. In the five out of the six months already elapsed of the present winter there have been twenty-one days with frost, and as yet the screened thermometer has not fallen below $23^{\circ} .6$. The winter (six months) with the lowest mean temperature at Greenwich is $1844-5$, when the mean was $38^{\circ} \cdot 8$, and the winters with the mean below $40^{\circ}$ were $1844-5$, I $854-5,1878-9,1885-6,1887-8$ and $1890-1$. The winter with the highest mean temperature was $1898-9$, when the mean for the six months was $45^{\circ} .4$, and the mean for each of the six months, with the exception of March, was above the average. The winters with the mean temperature above $44^{\circ}$ were $1845-6,1847-8$, $1848-9,1862-3,1876-7,1883-4,1897-8$ and $1898-9$. The mean for the five out of the six winter months already elapsed (1902-3) is $44^{\circ} \cdot 6$, so that it is most highly probable that the present winter will rank as one of the foremost for its general mildness.

Limiting the winter to a period of three monthsDecember, January and February-the coldest winter in the last sixty years at Greenwich is $1890-1$, with a mean temperature of $34^{\circ} 3$, or $5^{\circ}$ below the average, and during this period the mean temperature for December was $29^{\circ} .9$, January $33^{\circ} .9$ and February $39^{\circ} \cdot 1$. The second coldest winter was $1846-7$, with a mean of $34^{\circ} 5$, or $4^{\circ} .8$ below the average. In $1894-5$ the mean temperature for the winter was $35^{\circ .1}$, or $4^{\circ} \cdot 2$ below the average, and February, 1895, with a mean temperature of $29^{\circ} 3$, was the coldest of any winter month since 1841 , with the exception of $29^{\circ} \cdot 2$ in February, 1855 , and during this month (February, 1895) frost occurred in the screen on twenty-three nights, the lowest shade temperature being $6^{\circ} .9$, and for six consecutive days the thermometer did not once rise above the freezing point. The warmest winter (three months) was $1868-9$, with a mean of $44^{\circ .} 4$, or $5^{\circ} \cdot 1$ above the average. The second warmest winter was $1876-7$, with a mean of $43^{\circ} .7$, which is $4^{\circ} \cdot 4$ above the average. The winters (December to February) with the mean $3^{\circ}$ or more below the average are $1844-5,1846-7,1854-5$, I864-5, I878-9, $1879-80, \quad 1885-6$, I $890-1$, I $894-5$. The winters with the mean $3^{\circ}$ or more above the average are $1845-6, \quad 1848-9, \quad 1862-3, \quad 1865-6, \quad 1868-9, \quad 1876-7$, $1898-9$, and the present winter, ryo2-3, when the mean temperature was $3^{\circ} \cdot 1$ above the average. The mean temperature of February, I903, was $45^{\circ} \cdot 3$, which is the warmest since 1869 , and it was $16^{\circ}$ warmer than 1855 and i895. February had been cold for the previous three years, and it seemed probable that it would have been so this year, but experience has proved otherwise. At the commencement of the present winter, it was pretty confidently believed by many meteorologists that the winter would be severe, but such a belief has proved a most complete failure. It is, however, hoped that in the somewhat near future long period weather forecasts may be attempted. At present the forecaster is bound to admit his utter inability to form anything like an accurate estimate of our coming weather in England for more than twenty-four hours in advance, except when we are experiencing pronounced cyclonic or anticyclonic conditions, when we may with fair safety venture an opinion for, say, a week. The absolutely lowest winter temperatures at Greenwich (below $10^{\circ}$ ) are $4^{\circ}$. J January 9,$1841 ; 7^{\circ} .7$ February 12,$1845 ; 8^{\circ} .0$ December 25 , 1860; $6^{\circ} .6$ January 5,$1867 ; 9^{\circ} .8$ December 25,1870 ; and $6{ }^{\circ} .9$ February 8,1895 . The absolutely highest temperatures in each of the three winter months are December, $1848,620^{\circ}$; January, 1843 , $57^{\circ} \circ$; February, $1846,62^{\circ} 3$; $1868,61^{\circ} .7 ; 1869,61^{\circ} .6$; $1878,60^{\circ} .5 ; 1891,62^{\circ} 1$; $1899,63^{\circ} .9$. The winter of NO. I 742 , voL. 67$]$ r $885-6$ was severe and very prolonged, and it is apparently the only winter with skating on the waters around London in each of the four months December to March.

The average rainfall at Greenwich for the winter six months for the last sixty years is 11.82 inches, and the winters with the aggregate rainfall in excess of 14 inches are $1852-3,1865-6,1868-9,1872-3,1876-7,1880-1$, $1882-3,1896-7,1899-1900$. The wettest winter of the whole series was $1876-7$, with an aggregate rainfall of 18.72 inches. The driest winters, with a rainfall below 8 inches, were $1858-9,1873-4,1879-80,1890-1$ and $1897-8$. The driest winter was $1879-80$, with a tdtal rainfall of 5.54 inches. The aggregate rainfall for five out of the six winter months of the winter I902-3 is 7.3 inches, which is 4.5 inches less than the average for the six months during the last sixty years, and it is exceedingly improbable that the whole winter (October to March) will prove to be wet. Only two years have been wet at Greenwich out of the last fourteen years, but seven of the last fourteen winters have been wet, and ten of the last fourteen Decembers have been wet. The tail end of the present winter is proving very stormy, and for their destructive character the recent gales, as shown by the publications of the Meteorological Office, seem likely to prove as generally disastrous as any experienced for a long time past.

Chas. HaRding.

\section{A UNIQUE VARIABLE STAR.}

$\mathrm{M}$ ESSRS. MÜLLER and Kempf, of the Astrophysical Observatory of Potsdam, have recently announced the discovery of a variable star of so short a period that it must take a unique position among this class of phenomena. Up to this time the variables which went through a complete cycle of their light phases in the shortest time were those two stars situated in the rich star cluster $\omega$ Centauri; these bodies completed their periods in $7 \mathrm{~h} .1 \mathrm{I}^{\circ} 4 \mathrm{~m}$, and $7 \mathrm{~h} .42 \cdot 8 \mathrm{~m}$. Another variable running these rather close is that of $\mathrm{S}$. Antliæ, the period of which is $7 \mathrm{~h} .46 \cdot 8 \mathrm{~m}$. The new variable is, however, of a much shorter period than any of these, nearly one-half as short, occupying only four hours and a few seconds to complete its light changes.

The discoverers of this variable had their attention first brought to this object in their work on the photometric survey, in which it was noticed that there was a great difference between two measures of this $\operatorname{star}\left(\right.$ B.D. $+56^{\circ} 1400$, R.A. $=9$ h. $36 \mathrm{~m} .44 \mathrm{~s}$. , Decl. + $56^{\circ} 24^{\prime} \cdot 6$, I90o) that exceeded the usual error of observation. A closer examination of the star itself was then undertaken, and a series of observations extending over the year 1902, and part of this year, was made. The account of this research, recently published (Sitz. Ber. der K. Preuss. Ak. der Wiss., February 5 , $\mathrm{I}_{3} \mathrm{O}_{3}$, vii.), gives the details of the observations and the conclusions arrived at.

The diagram accompanying the paper shows that the light-changes at an epoch of minimum vary very quickly, the curve being quite pointed at these times. From minimum to maximum the light changes at rather a slower rate than from maximum to minimum, and at about maximum the star apparently changes its magnitude very little; so that the exact epoch of the maximum is not so easy to determine as that of the minimum. During these changes the magnitude varies from $8 \cdot 58$ to $7 \cdot 9$, and the length of the period, as at present determined, is $4 \mathrm{~h}$. om. $12.8 \mathrm{~s}$., with an error, as stated, of probably about $0^{\prime} 5$ s. For computing the times of minima the following equation is given :-

Min. = 1903 January 14, 4h. $32 \mathrm{~m}$. (Greenwich mean time) $+4 \mathrm{~h}$. om. $12 \cdot 8 \mathrm{~s}$. E. 